\title{
Triphalangeal thumbs-brachyectrodactyly syndrome
}

INSERM

\section{Source}

INSERM. (1999). Orphanet: an online rare disease and orphan drug data base.

Triphalangeal thumbs-brachyectrodactyly syndrome. ORPHA:2947

Triphalangeal thumbs-brachyectrodactyly syndrome is characterised by triphalangeal thumbs and brachydactyly of the hands. It has been described in four families and in one isolated case. Ectrodactyly of the feet and, more rarely, ectrodactyly of the hands were also reported in some family members. Transmission is autosomal dominant. 